\title{
Quantitative analysis of antimicrobial activity of Foeniculum vulgare: A review
}

\author{
Khaldoun J. Al-Hadid \\ The University of Jordan, Faculty of Science, Department of Biological Sciences, Amman 11942, Jordan
}

*Corresponding author: kalhadid@ju.edu.jo

\begin{abstract}
Foeniculum vulgare is a perennial herb that belongs to Apiaceae family. Traditionally, it is used as an antiseptic, carminative, digestive, diuretic, and expectorant agent. This is a systematic review on antimicrobial activity of Foeniculum vulgare using the Minimum Inhibitory Concentration (MIC) technique. Essential oil extract had more antimicrobial effect than the alcoholic extract of the same tested microorganisms. F. vulgare essential oil, alcoholic, hexane, and diethyl ether extracts had strong inhibitory activity against Bacillus cereus, Escherichia coli, Salmonella typhi, and Staphylococcus aureus. Essential oil extract had low MIC values for Bacillus cereus, Bacillus megaterium, Bacillus subtilis, Escherichia coli, Klebsiella sp., Pseudomonas aeruginosa, Salmonella typhi, Sarcina lutea, Shigella boydii, Shigella dysenteriae, Shigella shiga, Shigella sonnie, Staphylococcus aureus, and Streptococcus- $\beta$ haemolyticus. The alcoholic extract had low MIC values for Aspergillus flavus, Bacillus cereus, Candida albicans, Escherichia coli, Salmonella typhi, and Staphylococcus aureus. Hexane and diethyl ether extracts had low MIC values for Aspergillus flavus, Bacillus cereus, Candida albicans, Escherichia coli, Salmonella typhi, and Staphylococcus aureus. Microbial inhibition can be specific for the species. The antimicrobial activity strength of methanolic extract is similar to that of ethanolic extract. Acetone extract had lower MIC values than those for aqueous extract for the same tested microorganisms. Acetone, diethyl ether, and alcoholic extracts have stronger antifungal effects than essential oil. The essential oil extracted from $F$. vulgare leaves was not as effective as the essential oil extracted from its seeds. Foeniculum. vulgare extracts have high potential to be an effective antibiotic agent.
\end{abstract}

Keywords: antibacterial activity; antifungal activity; fennel; Foeniculum vulgare; medicinal plants.

Abbreviations: IZ_Inhibition Zone; MIC_Minimum Inhibitory Concentration; ppm_parts per million; TSST-1_Toxic Shock Syndrome Toxin 1.

\section{Introduction}

Foeniculum vulgare, also known as fennel, is native to southern Europe and the Mediterranean region. Nowadays, it is widely cultivated throughout the temperate and tropical regions of the world (Ferrara 1998). F. vulgare can reach a height of up to $2.5 \mathrm{~m}$, with a hollow stem. The leaves are finely dissected with the ultimate segments filiform (threadlike) of about $0.5 \mathrm{~mm}$ wide. The flowers are produced in terminal compound umbels. The fruit is a dry seed $4-10 \mathrm{~mm}$ long (Díaz-Maroto et al. 2005). The leaves and the fruit of $F$. vulgare are mainly used as ingredients in cosmetics and as flavoring substances for fish and meat to give them a strong aroma and taste (Ruberto et al. 2000). F. vulgare essential oil, which is produced by steam distillation of dried fruits, is used for flavoring purposes in Western countries (Husain 1994).

$F$. vulgare essential oil has antioxidant, antimicrobial, and hepatoprotective activity (Beaux et al. 1997; Marotti et al. 1993; Muckensturm et al. 1997; Özbek et al. 2003; Singh et al. 2002; Tanira et al. 1996). The essential oil extracted from $F$. vulgare seeds showed antibacterial activity against Bacillus cereus, Bacillus magaterium, Bacillus pumilus, Bacillus subtilis, Escherichia coli, Klebsiella pneumonia, Micrococcus lutus, Pseudomonas aeruginosa, Pseudomonos pupida, Pseudomonos syringae, Salmonella typhimurium, Shigella dysenteriae, Staphylococcus albus, Staphylococcus aureus, and Streptococcus haemolyticus (Anwar et al. 2009;
Diao et al. 2014; Gulfraz et al. 2008; Singh et al. 2002). This supports the traditional use of $F$. vulgare extracts as a cure for infectious diseases. In fact, significant inhibitory effect was detected against six Gram positive and nine Gram negative human pathogenic bacteria using $F$. vulgare oil (Kazemi et al. 2012). Moreover, an inhibitory effect using $F$. vulgare oil was detected against food-borne and seed-borne pathogenic bacteria such as Agrobacterium tumefaciens, Clavibacter michiganensis subsp. michiganensis, Erwinia carotovora pv. Carotovora, Listeria monocytogenes, Salmonella enteritidis, Salmonella typhimurium, and Xanthomonas axonopodis pv. vesicatoria (Soylu et al. 2009). The seed essential oil had inhibitory activity against Alternaria, Aspergillus fumigatus, Aspergillus niger, Aureobasidium, Fusarium solani, Penicillium, Phytophthora infestans, Rhizopus solani, Trichophyton rubrum, and three Candida albicans strains of different origins (Bansod and Rai 2008; Pai et al. 2010; Skrobonja et al. 2013; Soylu et al. 2006). This makes $F$. vulgare essential oil a good candidate as a bio-fungicide and as an alternative to the chemical fungicides against phytopathogenic fungi. In fact, the seed essential oil is able to prevent the mycelia growth responsible for food deterioration (Barkat and Bouguerra 2012). Anethole and fenchone, the main components of $F$. vulgare oil, have antifungal activity against Cladosporium cladosporioides, Penicillium helianthi, and Trichophyton mentagrophytes. 
However, Penicillium funiculosum, Penicillium ochrochloron, and Trichoderma viride were not inhibited by the essential oil (Mimica-Dukić et al. 2003; Singh et al. 2006). Moreover, the essential oil can reduce the mycelial growth and germination of Sclerotinia sclerotiorum (Soylu et al. 2007). The essential oil extracted from the stem showed a potential for controlling the multidrug- resistant Acinetobacter baumannii, a bacterial pathogen associated with hospital-acquired infections (Jazani et al. 2009). The essential oil suppresses the production of Staphylococcus aureus exotoxins, enterotoxins (SEs), and toxic shock syndrome toxin 1 (TSST-1). This suppression of Staphylococcus aureus toxins was attributed to the high amount of anethole in $F$. vulgare essential oil (Qiu et al. 2012). Therefore, anethole is an important antibiotic and food preservative agent that can be used in the pharmaceutical and food industries (Çetin et al. 2010; Martins et al. 2012).

The essential oils extracted from leaves and fruit (ripe and unripe) of $F$. vulgare showed antimicrobial activity to Alternaria alternate, Bacillus megaterium, Escherichia coli, Fusarium oxysporum, Paenihacillus larvae, and Rhizopus solani, (Araque et al. 2007; El-Adly et al. 2007; Gende et al. 2009; Özcan et al. 2006). Silver nanoparticles were made by the leaf extract of $F$. vulgare engaged with silver nitrate $\left(\mathrm{AgNO}_{3}\right)$. The silver nanoparticles of $F$. vulgare were tested for antibacterial activity in combination with antibiotics against Escherichia coli and Staphylococcus aureus. The different standard antibiotics (gentamicin, oxacillin, vancomycin, ampicillin, and amoxicillin) showed significant increases in their activity when combined with $F$. vulgare silver nanoparticles. The highest activity against Escherichia coli and Staphylococcus aureus was with combination of vancomycin (Bonde 2011). The essential oils extracted from the flowers and the roots significantly inhibited both Aspergillus parasiticus fungal growth and its production of aflatoxin (B1 and G1). The flower and root essential oil inhibited fungal growth by $65 \%$ and inhibited the production of aflatoxin (B1 and G1) by 98\% (Alinezhad et al. 2011).

Aqueous, ethanol, and ethyl acetate extracts of $F$. vulgare showed moderate antibacterial activity against Agrobacterium radiobacter pv. tumefaciens, Erwinia carotovora, Pseudomonas fluorescens, and Pseudomonas glycinea (Duško et al. 2006). Moreover, ethanol seed extract showed inhibitory activity against some pathogenic bacteria species such as Bacillus cereus, Bacillus subtilis, Enterobacter aerogenes, Enterobacter cloaceae, Kocuria rhizophila, and Staphylococcus aureus.

Hot water and acetone seed extracts showed inhibitory activity against Enterococcus faecalis, Escherichia coli, Pseudomonas aeruginosa, Salmonella typhi, Salmonella typhimurium 1, Shigella flexneri, and Staphylococcus aureus (Arora and Kaur 2007; Kaur and Arora 2009). The aqueous extract moderately inhibited the growth of three soil borne fungi, namely, Fusarium moniliforme, Macrophomina phaseoli, and Rhizocotina solani (Zahid et al. 2012). In fact, the aqueous extract at a concentration of $1.6 \mathrm{mg} / \mathrm{ml}$ was inhibitory to Aspergillus niger, Bacillus subtilis, Campylobacter jejuni, Escherichia coli, Pseudomonas aeruginosa, Penicillium chrysogenum, Staphylococcus aureus, and Salmonella typhi, (Abd El-Malak et al. 2010; Essawi and Srour 2000; Taie et al. 2013). This shows that $F$. vulgare aqueous extract could be used as a natural food preservative agent to enhance food shelf- life.

The methanol extracts of the seeds showed inhibitory activity against enteropathogenic bacteria (Bacillus pumilus, Helicobacter pylori, Staphylococcus aureus), and against Bacillus cereus, which is an important food poisoning pathogen (Alzoreky and Nakahara 2003; Dua et al. 2013; Mahady et al. 2005). Hexane extract of $F$. vulgare var. dulce had different inhibitory chemical compounds against multidrug-resistant Mycobacterium tuberculosis. In fact, the most inhibitory chemical compound extracted from the hexane extract against Mycobacterium tuberculosis was 2,4 undecadienal (Esquivel-Ferriño et al. 2012).

$F$. vulgare is an importance medicinal plant. Many research studies have been conducting to investigate the antimicrobial activity of this plant. The aim of this systematic review is to analyze the antimicrobial data in the literature using MIC values to learn what pathogens are inhibited by which part of $F$. vulgare, using which extraction method, and at what concentrations. This helps investigators to use this data analysis not only for ethanobotanical applications, but also for discovery of new antibiotics.

\section{Results}

\section{Essential oil extracted from seeds}

The antimicrobial activity of the essential oil extracted from seeds measured in MIC can be divided into six categories. The first category has the lowest MIC value of $0.5 \mathrm{ppm}$ and includes Staphylococcus aureus and Streptococcus-Bhaemolyticus. The second category has an MIC value of 1.0 ppm and includes Bacillus cereus, Bacillus megaterium, Bacillus subtilis, Escherichia coli, Pseudomonas aeruginosa, Shigella dysenteriae, and Shigella shiga. The third category has an MIC value of $1.5 \mathrm{ppm}$ and includes klebsiella sp. and Sarcina lutea. The fourth category has an MIC value of 2.0 ppm and includes Salmonella typhi and Shigella boydii. The fifth category has an MIC value of $5.0 \mathrm{ppm}$ and includes only one microorganism, Shigella sonnie. The sixth category includes many microorganisms with high MIC values (Table 1 and Figure 1).

\section{Alcoholic extracts from the seeds}

The classification of tested microorganisms according to MIC value can be divided into four categories, using methanolic and ethanolic extracts of the seeds. The first category has the lowest MIC value of $10 \mathrm{ppm}$ and includes Aspergillus flavus using the methanolic extract and Candida albicans using either methanolic or ethanolic extracts. The second category of $12.5 \mathrm{ppm}$ MIC value includes Aspergillus flavus using ethanolic extract, and Bacillus cereus and Staphylococcus aureus using methanolic extract for both organisms. The third category of $15 \mathrm{ppm}$ MIC value includes Bacillus cereus and Staphylococcus aureus using ethanolic extract, Escherichia coli and Salmonella typhi using either methanolic or ethanolic extracts. The fourth category includes many microorganisms with high MIC values (Table 2 and Figure 2).

\section{Aqueous and acetone extracts from the seeds}

High values of MIC were detected when aqueous or acetone extract of $F$. vulgare seeds was used. Relatively lower MIC values were obtained using acetone extract than aqueous extract (Table 3 and Figure 3).

\section{Hexane and diethyl ether extracts from the seeds}

Hexane and diethyl ether extracts had low MIC values for the tested microorganisms. However, hexane extract showed a 
Table 1. List of tested microorganisms and the antimicrobial activity of essential oil extracted from $F$. vulgare seeds expressed as MIC values.

\begin{tabular}{lccc}
\hline Microorganism & MIC Value & MIC Value (PPM) & Reference \\
\hline Alternaria sp. & $625 \mu \mathrm{g} / \mathrm{ml}$ & 625 & (Barkat and Bouguerra 2012) \\
Aspergillus fumigatus & $1250 \mu \mathrm{g} / \mathrm{ml}$ & 1,250 & (Barkat and Bouguerra 2012) \\
Aspergilus niger & $0.5(\%, \mathrm{v} / \mathrm{v}$ ) & 5,000 & (Bansod and Rai 2008) \\
Bacillus cereus & $1.0 \mu \mathrm{g} / \mathrm{ml}$ & 1 & (Kazemi et al. 2012) \\
Bacillus megaterium & $1.0 \mu \mathrm{g} / \mathrm{ml}$ & 1 & (Kazemi et al. 2012) \\
Bacillus subtilis & $1.0 \mu \mathrm{g} / \mathrm{ml}$ & 1 & (Kazemi et al. 2012) \\
Candida albicans & $0.4(\%, \mathrm{v} / \mathrm{v}$ ) & 4,000 & (Gulfraz et al. 2008) \\
Escherichia coli & $1.0 \mu \mathrm{g} / \mathrm{ml}$ & 1 & (Kazemi et al. 2012) \\
Fusarium solani & $91.1 \mathrm{mg} / \mathrm{ml}$ & 91,100 & (Anwar et al. 2009) \\
Fusarium sp. & $625 \mu \mathrm{g} / \mathrm{ml}$ & 625 & (Barkat and Bouguerra 2012) \\
Klebsiella sp. & $1.5 \mu \mathrm{g} / \mathrm{ml}$ & 1.5 & (Kazemi et al. 2012) \\
Micrococcus luteus & $2.1(\%, \mathrm{v} / \mathrm{v}$ ) & 21,000 & (Gulfraz et al. 2008) \\
Penicillium sp. & $1250 \mu \mathrm{g} / \mathrm{ml}$ & 1,250 & (Barkat and Bouguerra 2012) \\
Pseudomonas aeruginosa & $1.0 \mu \mathrm{g} / \mathrm{ml}$ & 1 & (Kazemi et al. 2012) \\
Pseudomonas putida & $0.6(\%, \mathrm{v} / \mathrm{v}$ ) & 6,000 & (Gulfraz et al. 2008) \\
Pseudomonas syringae & $2.6(\%, \mathrm{v} / \mathrm{v}$ ) & 26,000 & (Gulfraz et al. 2008) \\
Rhizopus & $1250 \mu \mathrm{g} / \mathrm{ml}$ & 1,250 & (Barkat and Bouguerra 2012) \\
Salmonella typhi & $2.0 \mu \mathrm{g} / \mathrm{ml}$ & 2 & (Kazemi et al. 2012) \\
Sarcina lutea & $1.5 \mu \mathrm{g} / \mathrm{ml}$ & 1.5 & (Kazemi et al. 2012) \\
Shigella boydii & $2.0 \mu \mathrm{g} / \mathrm{ml}$ & 2 & (Kazemi et al. 2012) \\
Shigella dysenteriae & $1.0 \mu \mathrm{g} / \mathrm{ml}$ & 1 & (Kazemi et al. 2012) \\
Shigella shiga & $1.0 \mu \mathrm{g} / \mathrm{ml}$ & 1 & (Kazemi et al. 2012) \\
Shigella sonnie & $5.0 \mu \mathrm{g} / \mathrm{ml}$ & 5 & (Kazemi et al. 2012) \\
Staphylococcus aureus & $0.5 \mu \mathrm{g} / \mathrm{ml}$ & 0.5 & (Kazemi et al. 2012) \\
Streptococcus- $\beta$ - haemolyticus & $0.5 \mu \mathrm{g} / \mathrm{ml}$ & 0.5 & (Kazemi et al. 2012) \\
Trichophyton rubrum & $1250 \mu \mathrm{gg} / \mathrm{ml}$ & 1,250 & (Barkat and Bouguerra 2012) \\
\hline
\end{tabular}

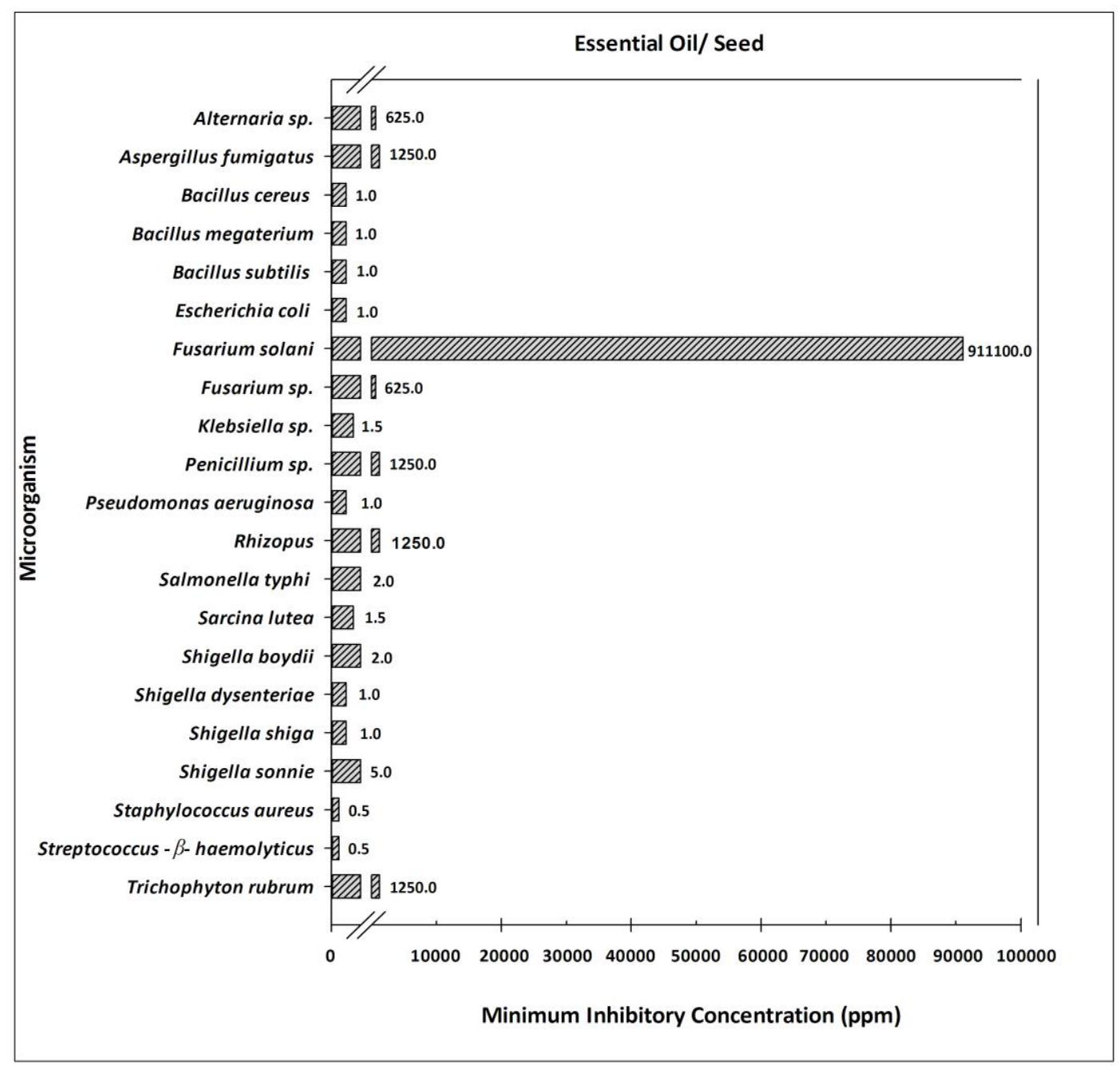

Fig 1. Minimum Inhibitory Concentration (MIC) in parts per million (ppm) of essential oil extracted from $F$. vulgare seeds on the tested microorganisms. Most of the experiments in the literature used essential oil of the seeds more than any other plant part. Essential oil extracted from the seeds had low MIC values for many microorganisms. 
Table 2. List of tested microorganisms and the antimicrobial activity of ethanolic and methanolic extracts of $F$. vulgare seeds expressed as MIC values.

\begin{tabular}{lcccc}
\hline Microorganism & $\begin{array}{c}\text { Extraction } \\
\text { Method }\end{array}$ & MIC Value & $\begin{array}{c}\text { MIC Value } \\
\text { (PPM) }\end{array}$ & Reference \\
\hline Aspergillus flavus & Ethanol & $12.5 \mu \mathrm{gg} / \mathrm{ml}$ & 12.5 & (Roby et al. 2012) \\
Aspergillus flavus & Methanol & $10 \mu \mathrm{g} / \mathrm{ml}$ & 10 & (Roby et al. 2012) \\
Bacillus cereus & Ethanol & $15 \mu \mathrm{g} / \mathrm{ml}$ & 15 & (Roby et al. 2012) \\
Bacillus cereus & Methanol & $12.5 \mu \mathrm{g} / \mathrm{ml}$ & 12.5 & (Roby et al. 2012) \\
Bacillus megaterium & Methanol & $3.7(\%, \mathrm{v} / \mathrm{v})$ & 37,000 & (Gulfraz et al. 2008) \\
Bacillus pumilus & Methanol & $8.33 \mathrm{mg} / \mathrm{ml}$ & 8,330 & (Dua et al. 2013) \\
Candida albicans & Ethanol & $10 \mu \mathrm{g} / \mathrm{ml}$ & 10 & (Roby et al. 2012) \\
Candida albicans & Methanol & $10 \mu \mathrm{g} / \mathrm{ml}$ & 10 & (Roby et al. 2012) \\
Escherichia coli & Ethanol & $15 \mu \mathrm{g} / \mathrm{ml}$ & 15 & (Roby et al. 2012) \\
Escherichia coli & Methanol & $15 \mu \mathrm{g} / \mathrm{ml}$ & 15 & (Roby et al. 2012) \\
Klebsiella pneumoniae & Methanol & $2.5(\%, \mathrm{v} / \mathrm{v}$ ) & 25,000 & (Gulfraz et al. 2008) \\
Listeria monocytogenes & Methanol & $>2640 \mathrm{mg} / \mathrm{L}$ & 2,640 & (Alzoreky and Nakahara 2003) \\
Micrococcus luteus & Methanol & $3.1(\%, \mathrm{v} / \mathrm{v}$ ) & 31,000 & (Gulfraz et al. 2008) \\
Pseudomonas aeruginosa & Methanol & $>33.33 \mathrm{mg} / \mathrm{ml}$ & 33,330 & (Dua et al. 2013) \\
Pseudomonas putida & Methanol & $1.4(\%, \mathrm{v} / \mathrm{v}$ ) & 14,000 & (Gulfraz et al. 2008) \\
Pseudomonas syringae & Methanol & $1.3(\%, \mathrm{v} / \mathrm{v}$ ) & 13,000 & (Gulfraz et al. 2008) \\
Salmonella infantis & Methanol & $>2640 \mathrm{mg} / \mathrm{L}$ & 2,640 & (Alzoreky and Nakahara 2003) \\
Salmonella typhi & Ethanol & $15 \mu \mathrm{g} / \mathrm{ml}$ & 15 & (Roby et al. 2012) \\
Salmonella typhi & Methanol & $15 \mu \mathrm{g} / \mathrm{ml}$ & 15 & (Roby et al. 2012) \\
Staphylococcus aureus & Ethanol & $15 \mu \mathrm{g} / \mathrm{ml}$ & 15 & (Roby et al. 2012) \\
Staphylococcus aureus & Methanol & $12.5 \mu \mathrm{g} / \mathrm{ml}$ & 12.5 & (Roby et al. 2012) \\
\hline
\end{tabular}

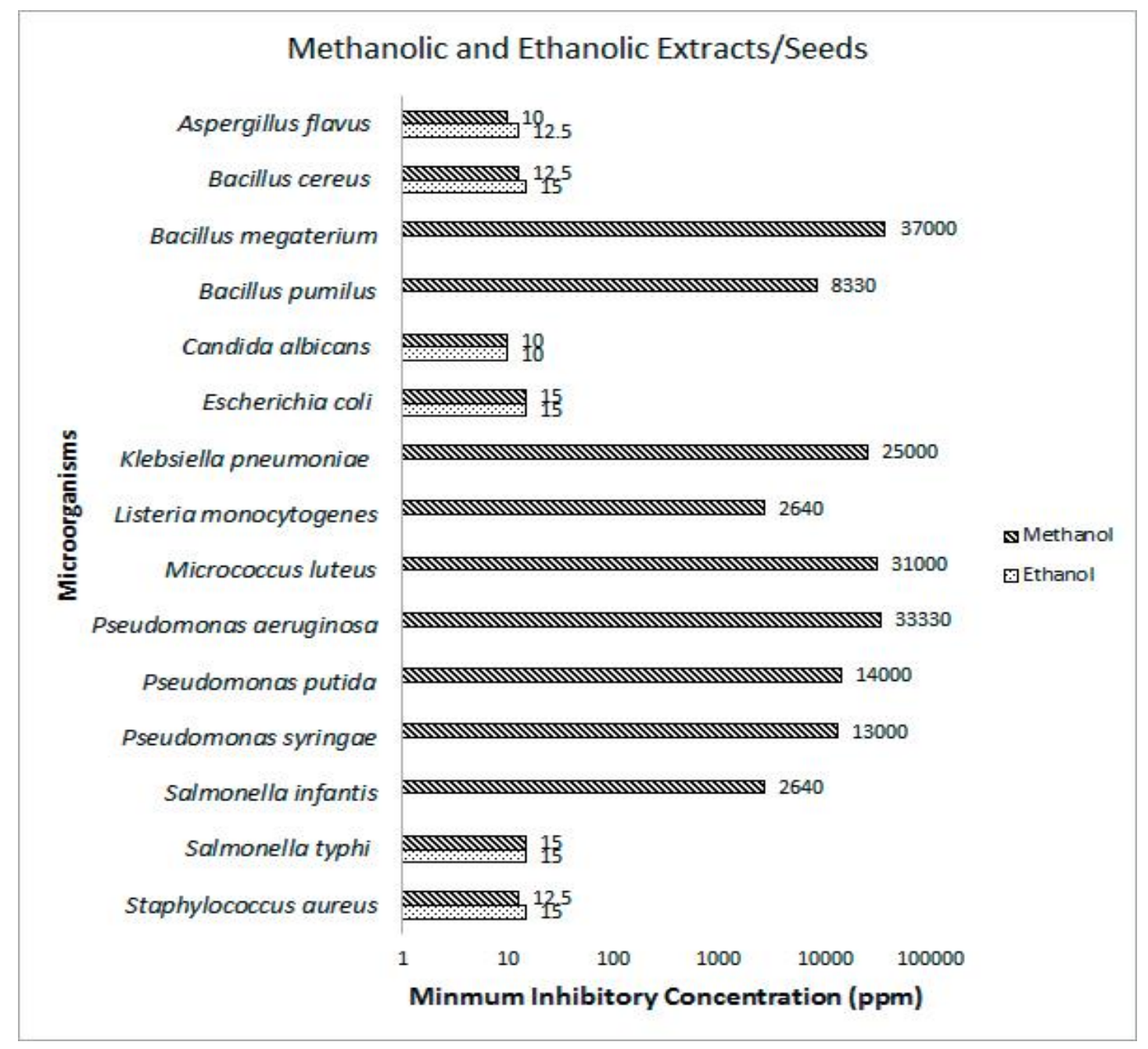

Fig 2. Minimum Inhibitory Concentration (MIC) in parts per million (ppm) of methanolic and ethanolic extracts from $F$. vulgare seeds on the tested microorganisms. Methanolic extract is the second most used extract after the essential oil extract. The methanolic and ethanolic extracts have similar MIC values. 
Table 3. List of tested microorganisms and the antimicrobial activity of acetone and aqueous extracts of $F$. vulgare seeds expressed as MIC values.

\begin{tabular}{|c|c|c|c|c|}
\hline Microorganism & Extraction Method & MIC Value (mg/ml) & MIC Value (ppm) & Reference \\
\hline Enterococcus faecalis & Acetone & 5 & 5,000 & (Kaur and Arora 2009) \\
\hline Enterococcus faecalis & Aqueous & 60 & 60,000 & (Kaur and Arora 2009) \\
\hline Escherichia coli & Acetone & 10 & 10,000 & (Kaur and Arora 2009) \\
\hline Escherichia coli & Aqueous & 60 & 60,000 & (Kaur and Arora 2009) \\
\hline Pseudomonas aeruginosa 2 & Acetone & 5 & 5,000 & (Kaur and Arora 2009) \\
\hline Pseudomonas aeruginosa 2 & Aqueous & 40 & 40,000 & (Kaur and Arora 2009) \\
\hline Salmonella typhi & Acetone & 5 & 5,000 & (Kaur and Arora 2009) \\
\hline Salmonella typhi & Aqueous & 30 & 30,000 & (Kaur and Arora 2009) \\
\hline Salmonella typhimurium 2 & Acetone & 5 & 5,000 & (Kaur and Arora 2009) \\
\hline Salmonella typhimurium 2 & Aqueous & 20 & 20,000 & (Kaur and Arora 2009) \\
\hline Shigella flexneri & Acetone & 10 & 10,000 & (Kaur and Arora 2009) \\
\hline Shigella flexneri & Aqueous & 20 & 20,000 & (Kaur and Arora 2009) \\
\hline Staphylococcus aureus & Acetone & 5 & 5,000 & (Kaur and Arora 2009) \\
\hline Staphylococcus aureus & Aqueous & 60 & 60,000 & (Kaur and Arora 2009) \\
\hline
\end{tabular}

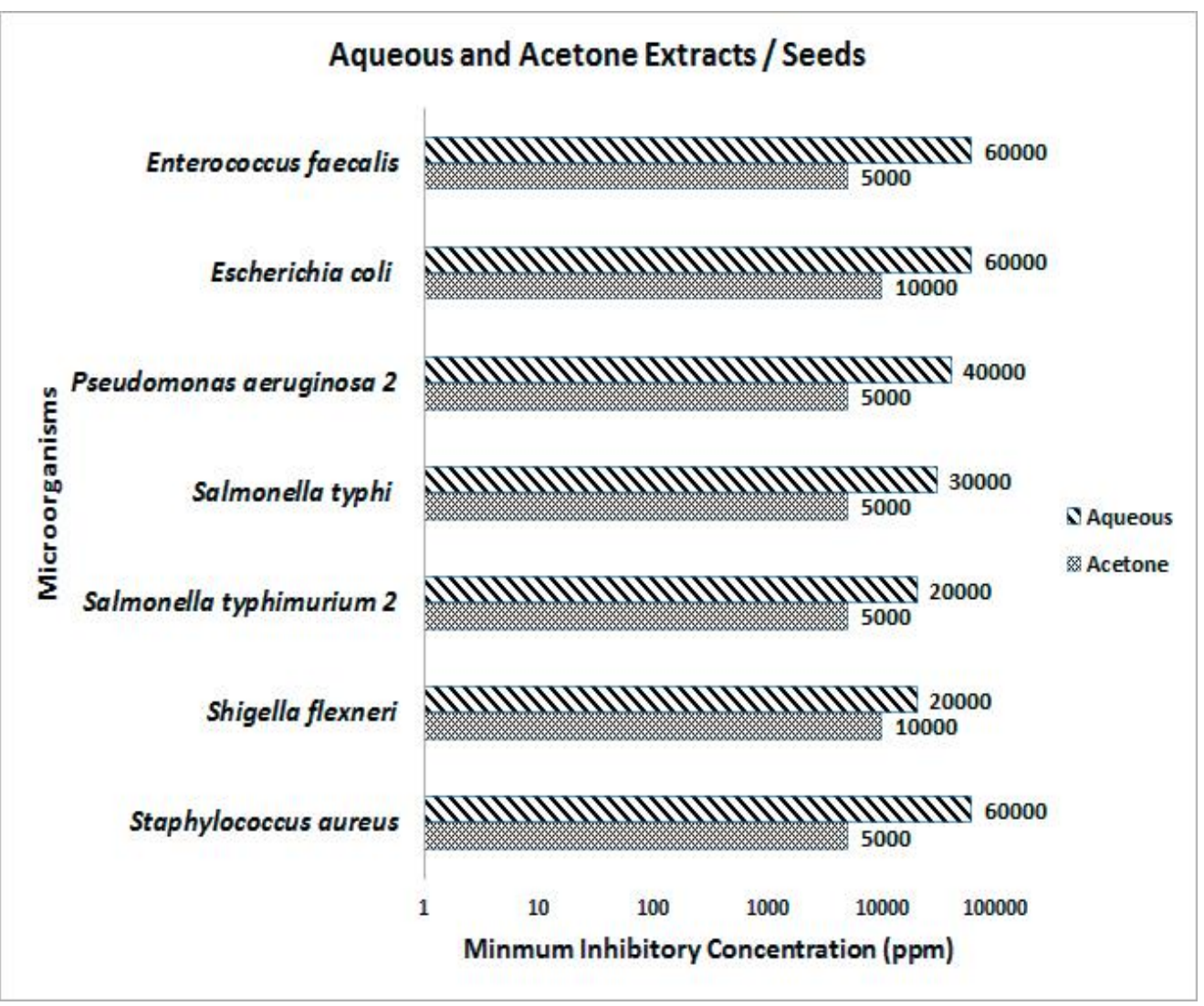

Fig 3. Minimum Inhibitory Concentration (MIC) in parts per million (ppm) of aqueous and acetone extracts from $F$. vulgare seeds on the tested microorganisms. The inhibitory effects of aqueous and acetone extracts are not as strong as the essential oil or the alcoholic extracts. The acetone extract has a stronger inhibitory effect than the aqueous extract.

Table 4. List of tested microorganisms and the antimicrobial activity of hexane and diethyl ether extracts of $F$. vulgare seeds expressed as MIC values.

\begin{tabular}{lcccc}
\hline Microorganism & Extraction Method & MIC Value $(\mu \mathrm{g} / \mathrm{ml})$ & MIC Value $(\mathrm{ppm})$ & Reference \\
\hline Aspergillus flavus & Hexane & 10 & 10 & (Roby et al. 2012) \\
Aspergillus flavus & Diethyl Ether & 12.5 & 12.5 & (Roby et al. 2012) \\
Bacillus cereus & Hexane & 12.5 & 12.5 & (Roby et al. 2012) \\
Bacillus cereus & Diethyl Ether & 15 & 15 & (Roby et al. 2012) \\
Candida albicans & Hexane & 12.5 & 12.5 & (Roby et al. 2012) \\
Candida albicans & Diethyl Ether & 15 & 15 & (Roby et al. 2012) \\
Escherichia coli & Hexane & 12.5 & 12.5 & (Roby et al. 2012) \\
Escherichia coli & Diethyl Ether & 15 & 15 & (Roby et al. 2012) \\
Salmonella typhi & Hexane & 15 & 15 & (Roby et al. 2012) \\
Salmonella typhi & Diethyl Ether & 17.5 & 10 & (Roby et al. 2012) \\
Staphylococcus aureus & Hexane & 10 & Roby et al. 2012) & (Roby et al. 2012) \\
Staphylococcus aureus & Diethyl Ether & 15 & & \\
\hline
\end{tabular}




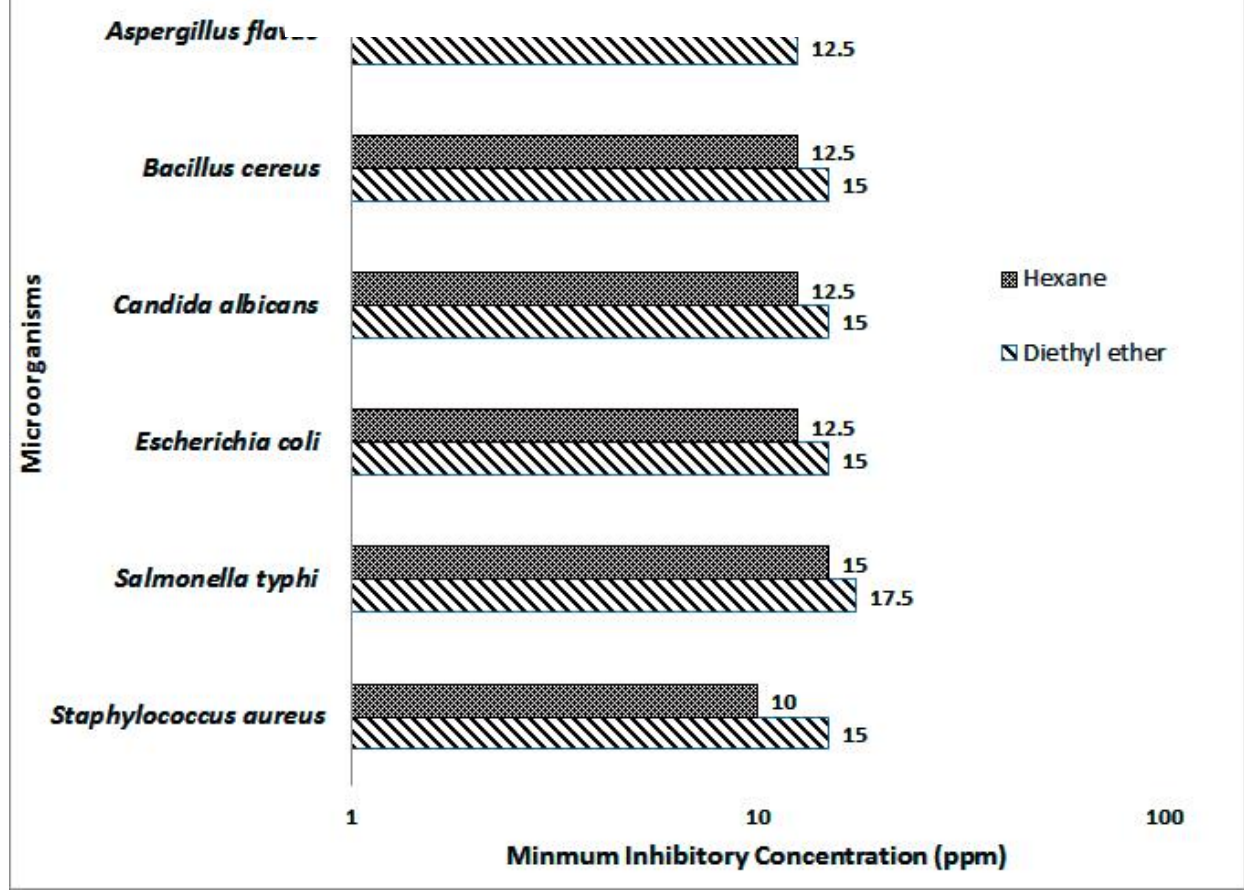

Fig 4. Minimum Inhibitory Concentration (MIC) in parts per million (ppm) of hexane and diethyl ether extracts. Hexane extract has similar antimicrobial activity as diethyl ether extract; however, hexane showed a lower MIC value than that of diethyl ether for all tested microorganisms.

lower MIC value than diethyl ether extract. For most of the tested microorganisms, the MIC value was $2.5 \mathrm{ppm}$ higher using diethyl ether extract than the MIC value using hexane extract for the same tested microorganism. The exception was Staphylococcus aureus, which had a difference of 5.0 ppm MIC value between the hexane and diethyl ether extracts (Table 4 and Figure 4).

\section{Essential oil extracted from the leaves}

Essential oil extracted from $F$. vulgare leaves had much higher MIC values that essential oil extracted from the seeds for the tested microorganisms, except for Aspergilus niger (Tables 1 and 5 and Figure 5).

\section{Discussion}

This is a mathematical approach to compare the data of different experiments of antimicrobial activity of $F$. vulgare using MIC values. MIC is the minimum concentration of the extract that is needed to inhibit the growth of a microorganism. High MIC value does not, necessary, mean that the extract is not inhibitory against the microorganism; however, a low MIC value definitely means the extract is very inhibitory. Essential oil is the most used extract of $F$. vulgare seeds to test for antimicrobial activity. Therefore, the number of microorganisms that showed antimicrobial activity using seeds of $F$. vulgare essential oil is more than the number of microorganisms that showed antimicrobial activity using any other extraction method. Some microorganisms had high MIC value, regardless of the extraction method, such as Micrococcus luteus, Pseudomonas putida, and
Pseudomonas syringae. Bacillus megaterium had a low MIC value using the essential oil, but had a high value using the methanolic extract. This could be due to the fact that MIC value of the methanolic extract was calculated from $(\%, v / v)$ not from $(w / v)$.

Some extracts showed high inhibitory antimicrobial activity. For instance, Bacillus cereus, Escherichia coli, Salmonella typhi, and Staphylococcus aureus have low MIC values when essential oil or alcoholic extract is used as an antimicrobial agent. However, the essential oil extract had more inhibitory effect than that of the alcoholic extracts on the same tested microorganisms. This could be explained by different scenarios. One scenario is that the inhibitory material that exists in the essential oil extract is different than what exists in the alcoholic extracts. The other scenario is that the nature of the inhibitory material is the same in the essential oil and the alcoholic extracts, but the concentration or/and the purity is higher in the essential oil than in the alcoholic extracts.

The inhibition of the microorganism can be specific for the species. For instance, by using essential oil extract, Pseudomonas putida and Pseudomonas syringae had high MIC values while Pseudomonas aeruginosa had a low MIC value. However, this is not always the case. For instance, Bacillus had a low MIC value, regardless of the species, using the essential oil extract. Interestingly, using methanolic extract, Bacillus cereus had a low MIC value, whereas Bacillus megaterium and Bacillus pumilus had high MIC values. In this case, the mode of inhibition is dependent on the species.

The antimicrobial activity of methanolic extract is similar to the ethanolic extract. However, methanolic extract had equivalent or lower MIC values than for the ethanol extract 
Table 5. List of tested microorganisms and the antimicrobial activity of essential oil extract of $F$. vulgare leaves expressed as MIC values.

\begin{tabular}{lccc}
\hline Microorganism & MIC Value $(\mu \mathrm{g} / \mathrm{ml})$ & $\begin{array}{c}\text { MIC } \\
\text { Value }(\mathrm{ppm})\end{array}$ & Reference \\
\hline Aspergilus niger & & 750 & Martins et al. 2012) \\
Escherichia coli & 750 & 750 & Martins et al. 2012) \\
Fusarium oxysporum & 750 & 750 & Martins et al. 2012) \\
Klebsiella pneumoniae & 750 & 500 & Martins et al. 2012) \\
Proteus mirabilis & 500 & 500 & (Martins et al. 2012) \\
Pseudomonas aeruginosa & 500 & 750 & Martins et al. 2012) \\
Salmonella enteridis & 750 & 250 & (Martins et al. 2012) \\
Staphylococcus aureus & 250 & 750 & \\
\hline
\end{tabular}

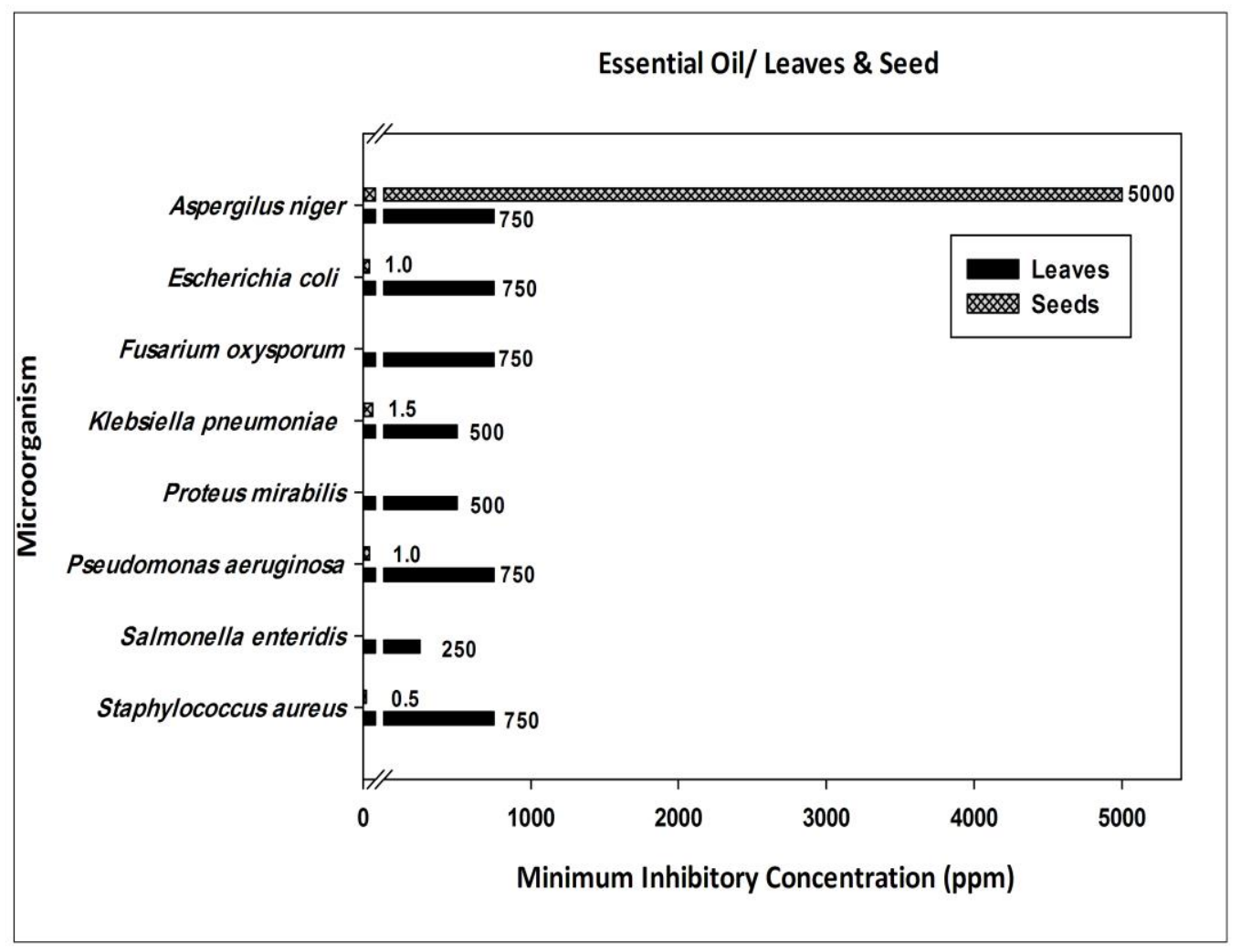

Fig 5. Minimum Inhibitory Concentration (MIC) in parts per million (ppm) of essential oil extracted from $F$. vulgare leaves on the tested microorganisms. Essential oil extracted from the leaves had higher MIC values than essential oil extracted from the seed for the same tested microorganisms, except Aspergilus niger.

for the same tested microorganisms. This is expected since the chemistry of methanol is close to the chemistry of ethanol. Therefore, the dissolved inhibitory materials of the extract could be similar with the same concentrations. Aqueous and acetone extracts of $F$. vulgare seeds had high MIC values for all tested microorganisms. However, acetone extract had lower MIC values than the MIC values of aqueous extract for the same tested microorganisms. This means that acetone extract of $F$. vulgare seeds is a stronger antimicrobial agent than that of aqueous extract.

Other extraction methods were used for $F$. vulgare seeds. Hexane and diethyl ester had low MIC values for some of the tested microorganisms. However, hexane had lower MIC values for all the tested microorganisms. Hexane, diethyl ether, and alcoholic extracts had lower MIC values than those of the essential oil for the tested fungi Aspegillus flavus and Candida albicans. This probably indicates that hexane, diethyl ether, and alcoholic extracts contain stronger antifungal agents than those of the essential oil.

Other plant parts, beside the seeds, were used as a source of essential oil. However, most research on $F$. vulgare was focused on the essential oil extracted from the seeds. The essential oil extracted from $F$. vulgare leaves was not as effective as the essential oil extracted from its seeds. However, the number of the tested microorganisms using the essential oil extracted from the seeds is much more than the number of tested microorganisms using the essential oil extracted from the leaves. Therefore, a fair comparison of the effectiveness of the extracted plant part cannot be made. However, for those tested microorganisms of both plant parts (leaves and seeds), antimicrobial strength, in most cases, is much more in the essential oil extracted from the seeds than that extracted from the leaves. The only exception microorganism is Aspergilus niger, which has lower MIC value for leaves than seeds.

\section{Methodology}

Articles related to studying the antimicrobial activity of $F$. vulgare were collected. Information was entered into Microsoft Excel and an Access database. To make the data analysis quantitative, only those experiments that reported MIC were considered. Since $F$. vulgare has a dry fruit, "fruits" mentioned in the articles was considered as "seeds." 
To make a scientific fair comparison between the different experiments in the literature, MIC units reported in the experiments were converted to parts per million ( $\mathrm{ppm}$ ). For those studies that used a value of MIC with bigger sign, the exact maximum MIC value was used in the analysis. Figures were generated using Microsoft Excel and SigmaPlot programs.

\section{Conclusion}

F. vulgare is an important medicinal plant. The plant extract has been proven to work as an antimicrobial agent for many tested microorganisms. The most common extract of $F$. vulgare is the essential oil of the seeds. The seeds have stronger antimicrobial activity than any other plant part. The essential oil extracted from the seeds does not work in the same manner as antimicrobial agent, when compared with the alcoholic extract of the seeds. This could be due to the different chemical compositions of the two extracts. Inhibition selectivity depends not only on the plant extract method, but also on the microorganism species. F. vulgare extract has high potential to be an effective antibiotic drug. Further experiments are needed to purify and fractionalize the crude extract to be tested in vivo as an antibiotic drug.

\section{References}

Abd El-Malak G, Nagib A, Youssef S (2010) Effect of adding herb extracts as antimicrobial and antioxidant on the quality characteristics of some juices. Ann Agric Sci (Cairo). 55:263-271

Alinezhad S, Kamalzadeh A, Shams-Ghahfarokhi M, Rezaee M-B, Jaimand K, Kawachi M, Zamani Z, Tolouei R , Razzaghi-Abyaneh M (2011) Search for novel antifungals from 49 indigenous medicinal plants: Foeniculum vulgare and Platycladus orientalis as strong inhibitors of aflatoxin production by Aspergillus parasiticus. Ann Microbiol. 61:673-681

Alzoreky N, Nakahara K (2003) Antibacterial activity of extracts from some edible plants commonly consumed in Asia. Int J Food Microbiol. 80:223-230

Anwar F, Ali M, Hussain AI, Shahid M (2009) Antioxidant and antimicrobial activities of essential oil and extracts of fennel (Foeniculum vulgare Mill.) seeds from Pakistan. Flavour Fragrance J. 24:170-176

Araque M, Rojas L, Usubillaga A (2007) Antibacterial activity of essential oil of Foeniculum vulgare miller against multiresistant gram-negative bacilli from nosocomial infections. Ciencia. 15:366-370

Arora DS, Kaur GJ (2007) Antibacterial activity of some Indian medicinal plants. J Nat Med. 61:313-317

Bansod S, Rai M (2008) Antifungal activity of essential oils from Indian medicinal plants against human pathogenic Aspergillus fumigatus and A. niger. World J Med Sci. 3:81-88

Barkat M, Bouguerra A (2012) Study of the antifungal activity of essential oil extracted from seeds of Foeniculum vulgare Mill. for its use as food conservative. Afr J Food Sci. 6:239-244

Beaux D, Fleurentin J, Mortier F (1997) Diuretic action of hydroalcohol extracts of Foeniculum vulgare var dulce (DC) roots in rats. Phytother Res. 11:320-322

Bonde S (2011) A biogenic approach for green synthesis of silver nanoparticles using extract of Foeniculum vulgare and its activity against Staphylococcus aureus and Escherichia coli. Bioscience. 3:59-63
Çetin B, Özer H, Cakir A, Polat T, Dursun A, Mete E, Öztürk E, Ekinci M (2010) Antimicrobial activities of essential oil and hexane extract of Florence fennel [Foeniculum vulgare var. azoricum (Mill.) Thell.] against foodborne microorganisms. J Med Food. 13:196-204

Diao W-R, Hu Q-P, Zhang H, Xu J-G (2014) Chemical composition, antibacterial activity and mechanism of action of essential oil from seeds of fennel (Foeniculum vulgare Mill.). Food Control. 35:109-116

Díaz-Maroto MC, Díaz-Maroto Hidalgo IJ, Sánchez-Palomo E , Pérez-Coello MS (2005) Volatile components and key odorants of fennel (Foeniculum vulgare Mill.) and thyme (Thymus vulgaris L.) oil extracts obtained by simultaneous distillation-extraction and supercritical fluid extraction. J Agric Food Chem. 53:5385-5389

Dua A, Garg G, Mahajan R (2013) Polyphenols, flavonoids and antimicrobial properties of methanolic extract of fennel (Foeniculum vulgare Miller). Eur J Exp Biol. 3:203-208

Duško BL, Čomić L, Solujić-Sukdolak S (2006) Antibacterial activity of some plants from family Apiaceae in relation to selected phytopathogenic bacteria. Kragujevac J Sci. 28:65-72

El-Adly AA, Abada EA, Gharib FA (2007) Antibacterial Effects of Low Power Laser Light and Volatile Oil of Fennel (Foeniculum vulgare var. dulce) on Gram-Positive and Gram-Negative Bacteria. Int J Agri Biol. 9:22-26

Esquivel-Ferriño PC, Favela-Hernández JMJ, Garza-González E, Waksman N, Ríos MY, Camacho-Corona MdR (2012) Antimycobacterial activity of constituents from Foeniculum vulgare var. dulce grown in Mexico. Molecules. 17:8471-8482

Essawi T, Srour M (2000) Screening of some Palestinian medicinal plants for antibacterial activity. J Ethnopharmacol. 70:343-349

Ferrara MMG (1998) Plantas medicinales del noreste de México. Grupo Vitro

Gende LB, Maggi MD, Fritz R, Eguaras MJ, Bailac PN , Ponzi MI (2009) Antimicrobial activity of Pimpinella anisum and Foeniculum vulgare essential oils against Paenibacillus larvae. J Essent Oil Res. 21:91-93

Gulfraz M, Mehmood S, Minhas N, Jabeen N, Kausar R, Jabeen K, Arshad G (2008) Composition and antimicrobial properties of essential oil of Foeniculum vulgare. Afr J Biotechnol. 7:4364-4368

Husain A (1994) Status report on aromatic \& essential oilbearing plants in NAM countries. I could not find it.

Jazani N, Zartoshti M, Babazadeh H, Ali-Daiee N, Zarrin S, Hosseini S (2009) Antibacterial Effects of Iranian Fennel Essential Oil on on isolates of Acinetobacter baumannii.. Pak J Biol Sci. 12(9):738-741.

Kaur GJ, Arora DS (2009) Antibacterial and phytochemical screening of Anethum graveolens, Foeniculum vulgare and Trachyspermum ammi. BMC Complementary Altern Med. 9:30.

Kazemi M, Mousavi E, Kharestani H (2012) Chemical compositions and antimicrobial activities of essential oils of Varthemia Persica, Foeniculum Vulgare and Ferula Lycia. Curr Res Bacteriol. 5:42-52

Mahady GB, Pendland SL, Stoia A, Hamill FA, Fabricant D, Dietz BM , Chadwick LR (2005) In vitro susceptibility of Helicobacter pylori to botanical extracts used traditionally for the treatment of gastrointestinal disorders. Phytother Res. 19:988-991

Marotti M, Dellacecca V, Piccaglia R, Giovanelli E, Palevitch D, Simon J (1993) Agronomic and chemical 
evaluation of three varieties of Foeniculum vulgare Mill. Acta Hort. 331:63-69

Martins MR, Tinoco MT, Almeida A , Cruz-Morais J (2012) Chemical composition, antioxidant and antimicrobial properties of three essential oils from Portuguese Flora. J Pharmacogn. 3:39-44

Mimica-Dukić N, Kujundžić S, Soković M, Couladis M (2003) Essential oil composition and antifungal activity of Foeniculum vulgare Mill. obtained by different distillation conditions. Phytother Res. 17:368-371

Muckensturm B, Foechterlen D, Reduron J-P, Danton P, Hildenbrand M (1997) Phytochemical and chemotaxonomic studies of Foeniculum vulgare. Biochem Syst Ecol. 25:353-358

Özbek H, Uğraş S, Dülger H, Bayram I, Tuncer I, Öztürk G, Öztürk A (2003) Hepatoprotective effect of Foeniculum vulgare essential oil. Fitoterapia. 74:317-319

Özcan MM, Chalchat J-C, Arslan D, Ates A, Ünver A (2006) Comparative essential oil composition and antifungal effect of bitter fennel (Foeniculum vulgare ssp. piperitum) fruit oils obtained during different vegetation. J Med Food. 9:552-561

Pai M, Prashant G, Murlikrishna K, Shivakumar K, Chandu G (2010) Antifungal efficacy of Punica granatum, Acacia nilotica, Cuminum cyminum and Foeniculum vulgare on Candida albicans: an in vitro study. Indian J Dent Res. $21: 334$

Qiu J, Li H, Su H, Dong J, Luo M, Wang J, Leng B, Deng Y, Liu J, Deng X (2012) Chemical composition of fennel essential oil and its impact on Staphylococcus aureus exotoxin production. World $\mathrm{J}$ Microbiol Biotechnol. 28:1399-1405

Roby MHH, Sarhan MA, Selim KA-H, Khalel KI (2012) Antioxidant and antimicrobial activities of essential oil and extracts of fennel (Foeniculum vulgare L.) and chamomile (Matricaria chamomilla L.). Ind Crops Prod.

Ruberto G, Baratta MT, Deans SG, Dorman H (2000) Antioxidant and antimicrobial activity of Foeniculum vulgare and Crithmum maritimum essential oils. Planta Med. 66:687-693

Singh G, Kapoor I, Pandey S, Singh U, Singh R (2002) Studies on essential oils: part 10; antibacterial activity of volatile oils of some spices. Phytother Res. 16:680-682

Singh G, Maurya S, De Lampasona M, Catalan C (2006) Chemical constituents, antifungal and antioxidative potential of Foeniculum vulgare volatile oil and its acetone extract. Food Control. 17:745-752

Skrobonja JM, Delić DN, Karaman MA, Matavulj MN , Bogavac MA (2013) Antifungal properties of Foeniculum vulgare, Carum carvi and Eucalyptus sp. essential oils against Candida albicans strains. Zb Matice Srp Prir Nauke. 195-202

Soylu EM, Soylu S, Kurt S (2006) Antimicrobial activities of the essential oils of various plants against tomato late blight disease agent Phytophthora infestans. Mycopathologia. 161:119-128

Soylu S, Soylu E, Evrendilek G (2009) Chemical composition and antibacterial activity of essential oils of bitter fennel (Foeniculum vulgare Mill. var. vulgare) and dill (Anethum graveolens L.) against the growth of food-borne and seedborne pathogenic bacteria. Ital J Food Sci. 21.

Soylu S, Yigitbas H, Soylu E, Kurt Ş (2007) Antifungal effects of essential oils from oregano and fennel on Sclerotinia sclerotiorum. J Appl Microbiol. 103:10211030

Taie HA, Helal M, Helmy W, Amer H (2013) Chemical composition and biological potentials of aqueous extracts of fennel (Foeniculum vulgare L). J Appl Sci Res. 9:17591767

Tanira M, Shah A, Mohsin A, Ageel A, Qureshi S (1996) Pharmacological and toxicological investigations on Foeniculum vulgare dried fruit extract in experimental animals. Phytother Res. 10:33-36

Zahid NY, Abbasi NA, Hafiz IA, Hussain A, Ahmad Z (2012) Antifungal activity of local fennel (Foeniculum vulgare Mill) extract to growth responses of some soil diseases. Afr J Microbiol Res. 6:46-51 